\title{
APC gene analysis in familial adenomatosis polyposis: 3 new mutations in Turkish population
}

\section{Familyal Adenomatozis Polipoziste APC geni analizi: Türk toplumunda 3 yeni mutasyon}

\author{
Ahmet Cevdet Ceylan', Gulay Ceylan ${ }^{2}$ \\ ${ }^{1}$ Ankara Yıldırım Beyazıt Üniversitesi, Tıp Fakültesi, Tıbbi Genetik Anabilim Dalı, Ankara, Türkiye \\ ${ }^{2}$ Ankara Şehir Hastanesi, Tıbbi Genetik Bölümü, Ankara, Türkiye
}

Dergiye Ulaşma Tarihi: 06.06.2020 Dergiye Kabul Tarihi: 18.06.2020 Doi: 10.5505/aot.2020.08931

\section{ÖZET}

GİRIŞ ve AMAÇ: Kolorektal kanser (KRK), tüm dünyada en sık görülen üç kanser tipi arasındadır. KRK hastalarının \%10'undan azı herediter KRK sendromlarını oluşturan germline mutasyonlar ile ilişkilidir. Bu hastalıkların başında adenomatöz poliple giden ailesel adenomatöz polipoziste (FAP) APC geni mutasyonları gelir. Çalışmamızda Türk toplumunda gözlenen APC mutasyonlarının tipini ve yapısını belirlemeyi amaçladık. YÖNTEM ve GEREÇLER: Kliniğimize FAP nedeniyle 24 hasta başvurdu. Bu hastalardan çalışma için periferik kan örneği alınıp, DNA izolasyonu yapıldı. Sekanslama işlemi Illumina MiSeq sisteminde yeni nesil dizileme yöntemi ile gerçekleştirildi. Veri analizleri QIAGEN Clinical Insight (QCITM) üzerinde gerçekleştirildi. BULGULAR: 24 hastanın 6'sında (\%25) patojenik mutasyon tespit edilirken, bir hastada iki farklı patojenik mutasyon (c.3183 3187delACAAA ve c.163C $>$ T) tespit edildi. c.2309C $>\mathrm{G}($ p.S770*) mutasyonu iki kardește tespit edildi. Bunlar dışında c.4393_4394delCC(p.S1465fs*3), c.4405_4406dupCA(p.Q1469fs*5), c.4312delA(p.T1438fs*35), c.3927_3931-_elAAAGA(p.E1309fs*4) mutasyonlar1 tespit edildi. TARTIŞMA ve SONUÇ: FAP'ın nedenlerinden olarak en sk APC genindeki mutasyonlar bildirilmiştir. Literatürde 2000 'den fazla mutasyon yer almaktadır. Bizim çalışmamızda literatür ile uyumlu olarak \%25 patojenik mutasyon saptandi. Bu mutasyonlardan 1. ekzondaki c.163C $>T$ (p.Q55*) ile 16. Ekzondaki c.4312delA(p.T1438fs*35), c.4405 4406dupCA (p.Q1469fs*5), ilk defa bizim çalışmamızda bildirilmektedir. Yeni mutasyonların bildirilmesi ile genin özellikle 16. ekzon dışında 1. ve 14. ekzonlarının da önemli yer alabileceğini ve yeni mutasyonlarla genin yapısının daha iyi anlaşılabileceği görülmektedir.

Anahtar Kelimeler: Ailesel adenomatöz polipoziste, APC, Yeni mutasyonlar

\begin{abstract}
INTRODUCTION: Colorectal cancer (CRC) is among the three most common types of cancer worldwide. Less than $10 \%$ of CRC patients are associated with germline mutations that form hereditary CRC syndromes. APC gene mutations in the familial adenomatous polyposis (FAP) leading to the adenomatous polyp are at the top of these diseases. In our study, we aimed to determine the type and structure of APC mutations observed in Turkish society. METHODS: 24 patients applied to our clinic for FAP. Peripheral blood sample was collected from these patients and DNA isolated. Sequencing was performed with the new generation sequencing method in the Illumina MiSeq system. Data analyzes were performed on QIAGEN Clinical Insight (QCITM).

RESULTS: Pathogenic mutation was detected in $6(25 \%)$ of 24 patients, while two different pathogenic mutations (c.3183_3187delACAAA and c.163C> T) were detected in one patient. The c.2309C > G (p.S770*) mutation was detected in two siblings. In addition, c.4393_4394delCC (p.S1465fs*3), c.4405_4406dupCA (p.Q1469fs*5), c.4312delA (p.T1438fs*35), c.3927_3931delAAAGA (p.E1309fs*4) mutations were detected.

DISCUSSION AND CONCLUSION: As the main causes of FAP, mutations in the APC gene have been reported most frequently. There are more than 2000 mutations in the literature. In our study, 25\% pathogenic mutations were detected in accordance with the literature. Of these mutations, c.163C> T (p.Q55*) in exon 1 and c.4312delA (p.T1438fs*35) in exon 16, are reported for the first time. With the reporting of new mutations, it is seen that especially the 1st and 14th exons besides the 16th exon can take place and the structure of the gene can be better understood with new mutations.
\end{abstract}

Keywords: Familial adenomatous polyposis, APC, Novel mutations

\section{GíRiş}

Kolorektal kanser (KRK), tüm dünyada en s1k görülen üç kanser tipi arasındadır. Genetik ve

Adress for correspondence: Ankara Şehir Hastanesi Genel Hastaneler Bloğu (mh1) -1. Kat (b1) tıbbi Genetik Bölümü Ankara - Türkiye Dr. Öğr. Üyesi Ahmet Cevdet CEYLAN 
çevresel faktörlerden etkilenen multifaktöriyel bir hastalıktır $(1,2,3)$. KRK'da bireyler aras1 değişkenliğin \%35'inden genetik faktörler sorumludur (4). Birinci derece akrabalarından birinde KRK olan kişilerde risk 2 kat artarken, aynı ailede 2 veya daha fazla kişide KRK varsa, ailenin diğer bireylerinde risk 4 kata çıkar (5). KRK hastalarının \%10'undan azı herediter KRK sendromlarını oluşturan germline mutasyonlar ile ilişkilidir (6). Bu herediter hastalıklar, adenomatöz poliple giden ailesel adenomatöz polipoziste (FAP) APC mutasyonları, Peutz-Jeghers Sendromu'nda STK11 mutasyonlar1, nonpolipozis olarak Lynch sendromu'nda DNA mismatch tamir (MMR) genlerindeki mutasyonlarla oluşurlar (6). $\mathrm{Bu}$ mutasyonların hepsi yüksek oranda penetrandır ve KRK açısından yüksek risk oluştururlar. $\mathrm{Bu}$ ailesel sendromlar KRK'nın çok düşük bir kısmından sorumlu olmasına rağmen, KRK'nın moleküler temeli için önemli olan bir gruptur. KRK'nın moleküler patogenezinde yer alan major genler, kanser sendromu tanısinı koymada, onkolojik sonuçların prognozunu değerlendirmede ve tedavi cevaplarını belirlemede önemli yer tutar (4).

KRK oluşumunda yer alan major genler, protoonkogen olarak KRAS, PIK3CA ve BRAF, tümör baskilayıc genlerden ise $A P C$ ve TP53 genleridir (4). APC geni, multifonksiyonel bir proteini kodlar, bu proteinin fonksiyonları arasında sinyal iletimi, hücre adezyon ve migrasyonu, mikrotübül birleşimi ve kromozom segregasyonu bulunur (7). APC somatik mutasyonları, tüm KRK'ların \%80'inden sorumludur (8). $A P C$ 'nin tümör baskılama kabiliyeti, Wnt yolağında ana etken olan intraselüler $\beta$-katenin seviyesini negatif olarak düzenlemesi ile ilişkilidir. $\mathrm{Bu}$ yüzden, $A P C$ 'nin inaktivasyonu $\beta$-katenin seviyesinin artmasına neden olur. Bununla ilişkili olarak farklı hedef genlerindeki aşırı ekspresyon adenom oluşumunu tetikler (8). APC geni, 5 numaralı kromozomun (5q21) uzun kolunda lokalizedir, 16 ekzonu vardır ve 2843 aminoasitlik bir proteini kodlar (8). APC genindeki mutasyonların çoğu, 1286 ve 1513. aminoasitler arasındaki mutasyona yatkın bölgede meydana gelir. Bu bölge, 16. ekzona denk gelir ve $\beta$-katenin bağlayıcı bölge ile çakışır (8). Somatik APC mutasyonları, sporadik KRK'ların \%80înde, 5q'nun heterozigosite kaybı ise, KRK vakalarının \%3040'inda bulunur $(9,10)$. Germline $A P C$ mutasyonları 178 ve 1580 . kodonlar arasindaki ucu kesilmiş varyantlardır ve normal proteinin üzerinde dominant negatif etki gösteren mutant peptidlerin oluşumuna neden olur $(8,11)$. Bu mutasyonlar ise, ailesel adenomatöz polipozis (FAP) olarak adlandırılan klasik hastalık formu ile ilişkilidir. Transkriptin 5' ve 3' uçlarında lokalize olan germline mutasyonlar ise hastalığın attenüe formuna (AFAP) neden olur. FAP ve AFAP otozomal dominant kalitım gösterirler. Fakat aile hikayesi olmayan vakalar da gösterilmiştir. APC taşıyıcılarının \%1025 'inde de novo mutasyonlar bildirilmiştir $(8,12)$. Son yayınlarda açıklanmış AP vakalarında, $\% 20-50$ oranında APC mozaisizmi raporlanmıştır $(13,14)$. De novo mutasyonlar her iki tip AP'de görülürken, mozaisizm ise daha çok AFAP hastalarında gözlenmiştir (13).

$\mathrm{Bu}$ çalışmada kliniğimize başvuran hastalarda tespit etmiş olduğumuz farklı $A P C$ gen mutasyonları, aile hikayeleri değerlendirilmiştir.

\section{GEREC VE YÖNTEM}

Kliniğimize 10.02.2019-01.03.2020 tarihleri arasinda, ailelerinde bulunan FAP nedeniyle ya da kolonoskopi sonrasinda 10 dan fazla polip saptanan 24 hasta başvurdu. Hastalardan aydınlatılmış onam formu alındı ve çalışma Ankara Yıldırım Beyazıt Üniversitesi klinik araştırmalar etik kurulunca onaylanmıştır.

Kan örnekleri EDTA tüplerine alınd. QIAcube ${ }^{\circledR}$ otomatik DNA izolasyon sistemi (Qiagen Inc. Mississauga, ON, Kanada) ile ekstrakte edilen hastaların DNA'sı. İzole edilmiş DNA örnekleri $-20^{\circ} \mathrm{C}$ 'de sakland.

Sekanslama için Qiagen panel sistemine uygun olarak APC geni için primer dizaynı yapıldı.Sekanslama işlemi Illumina MiSeq sisteminde (Illumina Inc., San Diego, CA, ABD) yeni nesil dizileme yöntemi ile gerçekleştirildi. Veri analizleri QIAGEN Clinical Insight (QCITM) Analiz yazılımı (QIAGEN, Hilden, Almanya) üzerinde gerçekleştirildi.

Varyant analizi için standart varyant yorumlamaya yönelik son ACMG / AMP kılavuzları kullanılmıştır. Patojenik varyantlar, kurum içi veri tabanında ve / veya literatürde iyi 
bilinen verilerle karșılaștırılmıștır. Literatür taramasinda The Human Gene Mutation Database (HGMD) veritabanı kullanılmıştır.

\section{BULGULAR}

Kliniğimize başvuran 24 hastanın 6'sında $A P C$ geninde (\%25) patojenik mutasyon tespit edilirken, bir hastada iki farklı patojenik mutasyon (c.3183_3187delACAAA ve c. $163 \mathrm{C}>\mathrm{T})$ tespit edildi. c.2309C $>\mathrm{G}\left(\mathrm{p} . \mathrm{S} 770^{*}\right)$ mutasyonu iki kardeşte tespit edildi. Bunlar dişında c.4393_4394delCC(p.S1465fs*3), c.4405_4406dupCA(p.Q1469fs*5), c.4312delA(p.T1438fs*35), c.3927_3931delAAAGA(p.E1309fs*4) mutasyonları tespit edildi. Tespit edilen mutasyonlar Tablo 1'de gösterilmektedir.

Tablo 1: Çalışmada saptanan APC genindeki mutasyonlar, mutasyonların neden olduğu protein değişimleri

\begin{tabular}{|c|c|c|c|c|c|c|c|c|}
\hline $\begin{array}{l}\text { Transkri } \\
\text { pt }\end{array}$ & $\begin{array}{l}\text { cDNA } \\
\text { değişimi }\end{array}$ & $\begin{array}{l}\text { Lok } \\
\text { asyo } \\
\text { n }\end{array}$ & $\begin{array}{l}\text { Protein } \\
\text { değişimi }\end{array}$ & \begin{tabular}{|l}
$\mathbf{d b S N}$ \\
\end{tabular} & $\begin{array}{l}\text { Değiş } \\
\text { im } \\
\text { tipi }\end{array}$ & $\begin{array}{l}\text { Varia } \\
\text { nt tipi }\end{array}$ & $\begin{array}{l}\text { Liter } \\
\text { atür }\end{array}$ & \\
\hline NM_000 & c.3183_3187 & Exon & p.Q1062 & rs587 & Nonse & Patoje & Diets 1 & 1 \\
\hline 038.6 & delACAAA & 16 & $*$ & $\begin{array}{l}77935 \\
2\end{array}$ & nse & nik & $(2018$ & \\
\hline \begin{tabular}{|l|} 
NM_001 \\
127511.3
\end{tabular} & c. $163 \mathrm{C}>\mathrm{T}$ & \begin{tabular}{|l|} 
Exon \\
01
\end{tabular} & p.Q55* & - & $\begin{array}{l}\text { Nonse } \\
\text { nse }\end{array}$ & $\begin{array}{l}\text { Patoje } \\
\text { nik }\end{array}$ & \begin{tabular}{|l|l}
$\mathrm{Bu}$ & 1 \\
çalış \\
$\mathrm{ma}$
\end{tabular} & 1 \\
\hline$\left|\begin{array}{l}\text { NM_001 } \\
127511.3\end{array}\right|$ & $\begin{array}{l}\text { c.4393_4394 } \\
\text { delCC }\end{array}$ & $\begin{array}{l}\text { Exon } \\
14\end{array}$ & $\begin{array}{l}\text { p.S1465 } \\
\text { fs*3 }\end{array}$ & - & $\begin{array}{l}\text { Frame } \\
\text { shift }\end{array}$ & $\begin{array}{l}\text { Patoje } \\
\text { nik }\end{array}$ & $\begin{array}{l}\text { Miyos } \\
\text { hi } \\
(1992 \\
\end{array}$ & 1 \\
\hline $\begin{array}{l}\text { NM_000 } \\
038.6\end{array}$ & $\begin{array}{l}\text { c.4405_4406 } \\
\text { dupCA }\end{array}$ & \begin{tabular}{|l|} 
Exon \\
16
\end{tabular} & $\begin{array}{l}\text { p.Q1469 } \\
\text { fs*5 }\end{array}$ & - & $\begin{array}{l}\text { Frame } \\
\text { shift }\end{array}$ & $\begin{array}{l}\text { Patoje } \\
\text { nik }\end{array}$ & \begin{tabular}{|l|l}
$\mathrm{Bu}$ \\
çalış \\
$\mathrm{ma}$
\end{tabular} & 1 \\
\hline $\begin{array}{l}\text { NM_000 } \\
038.6\end{array}$ & c. $4312 \mathrm{delA}$ & $\begin{array}{l}\text { Exon } \\
16\end{array}$ & $\begin{array}{l}\text { p.T1438 } \\
\text { fs*35 }\end{array}$ & - & $\begin{array}{l}\text { Frame } \\
\text { shift }\end{array}$ & $\begin{array}{l}\text { Patoje } \\
\text { nik }\end{array}$ & $\begin{array}{l}\mathrm{Bu} \\
\text { çalış } \\
\text { ma }\end{array}$ & 1 \\
\hline $\begin{array}{l}\text { NM_000 } \\
038.6\end{array}$ & c. $2309 \mathrm{C}>\mathrm{G}$ & $\begin{array}{l}\text { Exon } \\
16\end{array}$ & p.S770* & \begin{tabular}{|l} 
rs 106 \\
05033 \\
10
\end{tabular} & $\begin{array}{l}\text { Nonse } \\
\text { nse }\end{array}$ & $\begin{array}{l}\text { Patoje } \\
\text { nik }\end{array}$ & $\begin{array}{l}\text { Walp } \\
\text { ole } \\
(1995\end{array}$ & 2 \\
\hline \begin{tabular}{|l|} 
NM_000 \\
038.6
\end{tabular} & $\begin{array}{l}\text { c.3927_3931 } \\
\text { delAAAGA }\end{array}$ & \begin{tabular}{|l|} 
Exon \\
16
\end{tabular} & $\begin{array}{l}\text { p.E1309 } \\
\text { fs *4 }\end{array}$ & $\begin{array}{l}\text { rs121 } \\
91322 \\
4\end{array}$ & $\begin{array}{l}\text { Frame } \\
\text { shift }\end{array}$ & $\begin{array}{l}\text { Patoje } \\
\text { nik }\end{array}$ & $\begin{array}{l}\text { Miyos } \\
\text { hi } \\
(1992 \\
\end{array}$ & \\
\hline
\end{tabular}

\section{TARTIŞMA}

Kolorektal kanserler ciddi morbidite ve mortalite nedenidir. Herediter kolerektal kanserleri nedenleri ise polip içeren ve polipsiz olmak üzere ikiye ayrilır. 10'dan fazla adenomatöz poliple seyreden türüne Familyal adenomatöz polipozis (FAP) denmektedir. FAP'1n nedeni olarak en s1k APC genindeki mutasyonlar bildirilmiştir (9). Literatürde $A P C$ geninde 2000 'den fazla mutasyonun görüldüğü bildirilmiştir. Mutasyon tipleri arasında \%92'sinde protein yapısını ciddi şekilde bozan anlamsız (nonsense), çerçeve kaydıran (frameshift), delesyon tipinde mutasyonlar yer almaktadır. Yine yanlış anlamlı (missense) mutasyonlar da bildirilen APC mutasyonlarının \%6'sini oluşturmaktadır. $A P C$ geninde görülen mutasyonların literatürde yer alması genin fonksiyonunu daha iyi anlamayı, yeni hastalara daha doğru yönlendirme yapmayı sağlamaktadır. Çalışmamızda yeni mutasyonların etkisini literatüre kazandırmayı amaçladik.

Ankara Şehir Hastanesi, Genetik Hastalıklar Tanı Merkezi'ne kolonda 10'dan fazla polip görülmesi ve/veya birinci derece akrabalarında çok sayıda polip ve kolorektal kanser görülmesi nedeniyle 24 hasta başvurdu. $\mathrm{Bu}$ hastalara ilk olarak ayrıntılı klinik değerlendirme ve aile ağacı çizimi sonrası $A P C$ geninin tüm ekzonlarındaki mutasyonlar yeni nesil dizileme yöntemi ile araştırıldı. Daha önceki yaklaşımlarda en sık mutasyon gözlenen ekzonlardaki mutasyonlar araştırılırken yeni nesil dizileme yönteminin avantajı olarak genin tüm yap1s1 incelendi. 7 hastada patojenik değişiklik saptandı. Bu değişikliklerin tamamı protein yapısını ciddi olarak bozan indel ya da nonsense mutasyonlardi. Mutasyonların 5/7'si (\%71) 16. ekzonda yer almaktaydı. Bu mutasyonlardan c.3183_3187delACAAA (p.Q1062*) Diets ve arkadaşları tarafından, c.4393_4394delCC (p.S1465fs*3) ve c.3927_3931delAAAGA (p.E1309fs*4) mutasyonları Miyoshi ve arkadaşları tarafından c. 2309C $>\mathrm{G}$ (p.S770*) mutasyonu ise Walpole ve arkadaşları tarafından bildirilmişken, 3/7'si daha önce bildirilmemiștir (15-17). Birinci ekzondaki c.163C $>\mathrm{T} \quad$ (p.Q55*) ile 16. Ekzondaki c.4312delA (p.T1438fs*35), c.4405_4406dupCA (p.Q1469fs*5), mutasyonları ilk defa bizim çalışmamızda bildirilmektedir.

Kohortomuzdaki hastalardan birinde 1 . ekzondaki c.163C>T (p.Q55*) mutasyonu ile 16. ekzondaki c.3183_3187delACAAA (p.Q1062*) mutasyonu birlikte görüldü. $A P C$ geni ile ilişkili kanser patofizyolojisinde germline bir mutasyona eklenen ikinci bir somatik mutasyonun eklenmesi olarak bildirilmiştir (16). Ancak hastamızda 2 
mutasyonun da bulunması hastanın kliniğinde de olduğu gibi erken başlangıçlı bir kliniğe neden olabilir. Ayrıca bulunan iki mutasyon aynı allelde bulunması ihtimalinde 1. ekzondaki protein terminasyonu yapan mutasyon nedeniyle 16. ekzondaki mutasyon translasyona uğrayamayacak ve etkisi olmayabilir.

Literatürde FAP tanis1 alan hastalarda APC mutasyon oranı ile ilgili farklı oranlar bildirilmiştir (15). 100'den fazla polipi olan hastalarda \%50'nin üzerinde mutasyon saptanmışken, 10 ve 100 arasında polibi olan hastalarda daha az oranda görülebildiği bildirilmiştir. Bunun yanında APC dışındaki genlerden özellikle MUTHY'de mutasyon oranın arttığ 1 bildirilmiştir. Yine bir çalışmada $A P C$ ve $M U T H Y$ genlerindeki mutasyonların birlikte olabileceği de gösterilmiştir (16). Türk toplumunda ise $A P C$ mutasyon dağ 11 1.mı ve etkisi ile ilgili çok az çalışma vardır. Tunca ve arkadaşları 6 FAP ailesinin 3'ünde mutasyon tespit edebilmişken, Dalkılıç ve arkadaşları 30 hastada hiç mutasyon saptayamadıklarını bildirmişlerdir (4). Bizim çalışmamızda ise 24 bireyden 6'sinda mutasyon edilebilmesi literatür ile uyumluydu. Klinik olarak FAP tanısı almış olan hastalarda $A P C$ mutasyonu saptanamadığı taktirde diğer ilişkili genlere bakılması önerilmektedir. Erdem ve arkadaşları ise kolorektal kanser hastalarında geniş bir gen paneli araştırarak 136 hastada hastalık nedeni olabilecek germline mutasyon tespit edebilmişlerdir (19). Ayrıca çok sayıda klinik önemi belirsiz değişiklik bulmuşlardır. Yine benzer şekilde Diets ve arkadaşları ise benzer bir paneli kullanmışlar ve benzer oranlarda mutasyon tespit edebilmişlerdir (15). $\mathrm{Bu}$ çalışmalar kolon kanseri etiyolojisinde birden çok genetik neden olduğunu ortaya koymaktadır. Adenomatöz polipozis görülenlerin herediter olma ihtimali artmakta ve yapılan çalışmalarda $A P C$ başta olmak üzere bir çok gen sorumlu tutulmaktadır. Ayrıca polipozis olmadan da herediter kolon kanserlerinin genetik etiyolojinin araştırılmasında çok sayıda gen içeren panellerin önemli olduğu görülmektedir (19).

Çalışmamızda FAP tanısı alan 24 hasta bireyde $A P C$ geninde 7 farklı mutasyon tespit edildi ve bu mutasyonların 3'ü daha önce literatürde bulunmamaktaydi. Yeni mutasyonların bildirilmesi ile APC geninin özellikle 16. ekzon dişında 1 . ve 14 . ekzonlarının da önemli yer alabileceğini ve yeni mutasyonlarla genin yapisının daha iyi anlaşılabileceği görülmektedir.

\section{References}

1. Bray F, Ferlay J, Soerjomataram I, et al. Global cancer statistics 2018: GLOBOCAN estimates of incidence and mortality worldwide for 36 cancers in 185 countries. CA Cancer J Clin. 2018;68:394424.

2. Byrne RM, Tsikitis VL. Colorectal polyposis andinherited colorectal cancer syndromes. Ann Gastroenterol. 2018;31:24-34.

3. Kirkegaard H, Johnsen NF, Christensen J, et al. Association of adherence to lifestyle recommendations and risk of colorectal cancer: a prospective Danish cohort study. BMJ. 2010;341:c5504.

4. $\mathrm{Ng} \mathrm{C}, \mathrm{Li} \mathrm{H}, \mathrm{Wu}$ WKK, et al. Genomics and metagenomics of colorectal cancer. J Gastrointest Oncol. 2019; 10(6):11641170.

5. Kampman E. A first-degree relative with colorectal cancer: what are we missing? Cancer Epidemiol Biomarkers Prev. 2007;16:1-3.

6. Stoffel EM, Mangu PB, Gruber SB, et al. Hereditary colorectal cancer syndromes: American Society of Clinical Oncology Clinical Practice Guideline endorsement of the familial risk-colorectal cancer: European Society for Medical Oncology Clinical Practice Guidelines. J Clin Oncol. 2015;33:209-17.

7. Hankey W, Frankel WL, Groden J. Functions of the APC tumor suppressor protein dependent and independent of canonical WNT signaling: implications for therapeutic targeting. Cancer Metastasis Rev. 2018; 37:159-172

8. Lorca V, Garre P. Current status of the genetic susceptibility in attenuated adenomatous polyposis. World J Gastrointest Oncol. 2019;11(12):11011114.

9. Fearnhead NS, Britton MP, Bodmer WF. The ABC of APC. Hum Mol Genet 2001; 10(7):721-733.

10. Zhang L, Shay JW. Multiple Roles of APC and its Therapeutic Implications in Colorectal Cancer. J Natl Cancer Inst. 2017; 109:djw332

11. Sieber OM, Segditsas S, Knudsen AL, et al. Disease severity and genetic pathways in attenuated familial adenomatous polyposis vary greatly but depend on the site of the germline mutation. Gut. 2006; 55:14401448

12. Aretz S, Uhlhaas S, Caspari R, et al. Frequency and parental origin of de novo 
APC mutations in familial adenomatous polyposis. Eur J Hum Genet 2004;12: 5258

13. Spier I, Drichel D, Kerick M, et al. Lowlevel APC mutational mosaicism is the underlying cause in a substantial fraction of unexplained colorectal adenomatous polyposis cases. J Med Genet. 2016; 53: 172-179

14. Jansen AM, Crobach S, Geurts-Giele WR, et al. Distinct Patterns of Somatic Mosaicism in the APC Gene in Neoplasms From Patients With Unexplained Adenomatous Polyposis. Gastroenterology. 2017; 152: 546-549.e3

15. Diets IJ, Waanders E, Ligtenberg MJ, van Bladel DAG, Kamping EJ, Hoogerbrugge PM, et al. High Yield of Pathogenic Germline Mutations Causative or Likely Causative of the Cancer Phenotype in Selected Children with Cancer. Clin Cancer Res. 2018;24(7):1594-603.
16. Miyoshi $Y$, Ando H, Nagase H, Nishisho I, Horii A, Miki Y, et al. Germ-line mutations of the APC gene in 53 familial adenomatous polyposis patients. Proc Natl Acad Sci U S A. 1992;89(10):4452-6.

17. Walpole IR, Kool DA, Edkins T, Creegan R, Levitt S, Francis ST, et al. Genetic counselling and gene mutation analysis in familial adenomatous polyposis in Western Australia. Med J Aust. 1995;162(9):464-7.

18. Şahin A, Tunç N, Yalnız M. Elazı̆̆ Bölgesinde Attenue Familyal Adenomatöz Poliposis coli (AFAP) Olgularında APC Gen Mutasyonlarının Araştırılması. F.Ü. Sağlık Bilimleri Veteriner Dergisi, 2019; 33:77-81

19. Erdem HB, Bahsi T. Spectrum of germline cancer susceptibility gene mutations in Turkish colorectal cancer patients: a single center study. Turk J Med Sci. 2020. 